\title{
DIFERENÇA DE TRATAMENTO EM RAZÃO DE GÊNERO: TRATAMENTO DISCRIMINATÓRIO DA MULHER NO CRIME DE ABORTO
}

\section{DIFFERENCE IN TREATMENT BASED ON GENDER: DISCRIMINATORY TREATMENT OF WOMEN IN THE CRIME OF ABORTION}

\section{Bruna de Souza Fernandes ${ }^{1}$}

RESUMO: Este artigo tem como tema o tratamento discriminatório da mulher no crime de aborto. O objetivo geral é analisar se o texto legal que define o crime de aborto é favorável à implementação do direito à igualdade de gênero para as mulheres. Acerca da metodologia utilizada, cabe destacar que o método foi dedutivo, a pesquisa foi exploratória, bibliográfica e documental, e os dados foram analisados de forma qualitativa. Com a pesquisa, pôde-se observar que a criminalização do aborto não atende ao princípio da igualdade e corrobora com o tratamento discriminatório de gênero. Nesse sentido, foi exposto que os julgamentos da ADPF n. 54 e do HC n. 124.306 pelo STF trouxeram avanço na tratativa do tema, mas há projetos de lei que ameaçam agravar a situação de desigualdade das mulheres.

Palavras-chave: Direitos humanos. Igualdade de gênero. Direitos das mulheres.

ABSTRACT: The issue analyzed by this article is about the discriminatory treatment of women in the crime of abortion. The main purpose is to analyze whether the legal text that defines the crime of abortion is favorable to the implementation of Gender Equality. The methodology that has been used, the deductive method, was exploratory, bibliographic, and documental. The data has been analyzed in a qualitative manner. Due to the research, it has become possible to observe that abortion criminalization has not provided an answer in accordance with the principle of equality and has deemed society to a discriminatory treatment of women. In this sense, the judgements of the ADPF n. 54 and HC n. 124.306 by the STF (Brazilian Supreme Court) were brought into light demonstrating a step forward on the matter; however, there are some bills that have threatened to aggravate the situation of inequality.

Keywords: Human rights. Gender equality. Women rights.

1 Bacharela em Relações Internacionais e Bacharela em Direito pela Universidade do Sul de Santa Catarina (Unisul). Pós-graduanda em Direito Público pela Esmesc/ Unisul. Advogada, conciliadora judicial. Atualmente, exerce a função de residente judicial. E-mail: bruna.fernandes-int@hotmail.com. 


\section{INTRODUÇÃO}

O tema do presente artigo consiste na diferença de tratamento da mulher em razão de gênero no crime de aborto. Para Strey (2001), o gênero não é inato, mas uma construção cultural, um produto de relações históricas e sociais, baseadas em diferenças percebidas entre os dois sexos, que não decorrem da biologia ou fisiologia, e que esclarecem as reiteradas desigualdades de todos os tipos entre homens e mulheres.

Essa consideração inicial é imprescindível para a análise do presente estudo, uma vez que houve uma convenção cultural no sentido de atribuir à mulher condição de inferioridade, legitimando violências e discriminações que ocorrem em razão de seu gênero, inclusive na área jurídica. No âmbito do Direito Penal, o tratamento discriminatório da mulher pode ser constatado em dispositivos legais, na interpretação da lei, por meio de julgados fundados em padrões estereotipados de conduta, e também na adoção de determinados procedimentos, como era o caso do uso de algemas durante o parto.

O objetivo geral do estudo é analisar se o texto legal que define o crime de aborto é favorável à implementação do direito à igualdade de gênero para as mulheres. Sobre os objetivos específicos, pode-se ressaltar que esses consistem em: definir a igualdade; conhecer o tratamento legal dado às mulheres no crime de aborto; analisar a diferença de tratamento da mulher em razão do gênero no crime de aborto.

O estudo apresenta relevância por tratar de questões de ordem pública internacional, afetando, direta ou indiretamente, todas as pessoas, mas principalmente todas as mulheres. $\mathrm{O}$ trabalho é importante para a comunidade acadêmica, em geral, por ser um tema que requer discussões, possibilitando a confecção de trabalhos futuros. Para a autora, este estudo possui especial importância, uma vez que atende à sua área de interesse de pesquisa, qual seja: Direito Internacional dos Direitos Humanos. 
Acerca da metodologia utilizada para o desenvolvimento deste estudo, cabe mencionar que o método utilizado foi o dedutivo, a pesquisa teve caráter exploratório, e os dados foram coletados de forma bibliográfica e documental, por meio de fontes primárias e secundárias. Ademais, os dados foram coletados com o uso de ficha de leitura, analisados de forma qualitativa e apresentados em forma de artigo.

\section{IGUALDADE}

O princípio da igualdade representa uma das ideias da modernidade. Em tempos passados, a desigualdade era aceita sem reclamação ou esperança de mudança, era considerada uma ocorrência natural ou proveniente da vontade divina. Todavia, há três séculos, ideais igualitários agitam os espíritos e movem as pessoas à luta por mudanças políticas, econômicas e sociais (FERREIRA FILHO, 2014).

Conforme o fundamento da igualdade, todos nascem e vivem com as mesmas obrigações e os mesmos direitos perante o Estado. A igualdade foi idealizada na Revolução Francesa, e atingida com a abolição de privilégios que eram concedidos à nobreza e ao clero. Dessa forma, quando todos passaram a ter o mesmo tratamento ante a lei, atingiu-se a igualdade formal (PINHO, 2015).

Para Moraes (2016), a igualdade formal, também chamada de igualdade civil ou jurídica, é representada pela elaboração, interpretação e aplicação igualitária das normas jurídicas, sem diferenciações arbitrárias de tratamento, ou seja, sem discriminações ou privilégios.

De acordo com Miranda (2016), privilegiadas são as pessoas que têm direitos não concedidos aos demais ou às pessoas na mesma situação. Discriminadas, por sua vez, são as pessoas a quem não são atribuídos os direitos conferidos ao conjunto de pessoas ou a quem são impostos encargos não 
fixados aos demais.

Todavia, apesar de os direitos serem os mesmos para todos, nem todos se encontram em igualdade de condições para exercê-los. Assim faz-se necessário que essas condições sejam criadas, ou recriadas, por meio da transformação da vida e das estruturas em que as pessoas interagem (MIRANDA, 2016).

Nesse sentido, Pinho (2015) destaca as diferenças entre a igualdade formal e material. Para o autor, enquanto a primeira considera que todos são iguais perante a lei, a segunda implica a igualdade de fato. Desse modo, a igualdade formal, por si só, caracteriza-se como insuficiente, e o Estado deve criar mecanismos para que todos possam, efetivamente, gozar dos mesmos direitos.

O princípio constitucional da igualdade não determina o que é igual, mas apenas dispõe no sentido de que o que for igual seja tratado igualmente, enquanto o que não for igual deva ser tratado de forma desigual. Desse modo, pode-se destacar que a questão da igualdade envolve a proporcionalidade e a ponderação de valores, ao invés da arbitrariedade (MIRANDA, 2016).

Acerca da relação entre as igualdades formal e material, Miranda (2016) ressalta que a igualdade jurídica é condição preliminar para o alcance da igualdade real, tendo em vista que esta não subsistiria sem a garantia do direito. Nesse sentido, uma sociedade de iguais somente será formada se os seus membros tiverem, antes de tudo, o direito de ser iguais. Se o direito não for garantido, a igualdade carecerá de efeito.

No que concerne à questão da igualdade de gênero, mais especificamente, Castilho (2015, p. 369) destaca que a igualdade formal é o início para seu alcance:

A principal solução para que se alcance a igualdade de gênero é jurídica. As legislações nacionais devem cuidar para que os direitos acordados na Convenção sobre a Eliminação de Todas as Formas de Discriminação contra as Mulheres 
sejam inseridos em todos os âmbitos, seja social, político ou de trabalho. Este é o caminho inicial para que se destruam os estereótipos negativos. Com a lei será possível dar início ao processo de eliminação da violência contra as mulheres: pobreza, falta de educação, precariedade de atendimento de saúde, uso da mulher em conflitos armados e alienação da mulher dos cargos de poder e dos meios de comunicação.

Para Castilho (2015), falta participação masculina no processo de igualdade de gênero. Do mesmo modo, é insuficiente a vontade política por parte dos Estados, que, geralmente, são governados por homens. A falta de reconhecimento da contribuição social das mulheres e sua baixa participação nos postos de tomada de decisão contribuem para a continuidade da mulher em situação inferior. Dessarte, por faltar educação, há pouca sensibilização até entre as próprias mulheres.

No Brasil, a Constituição Federal de 1988 apresentou diversas disposições que vedam expressamente a discriminação entre homens e mulheres, atendendo à igualdade formal, bem como trouxe a previsão de medidas diferenciadas, que visam à diminuição da desigualdade existente, construída em razão do gênero, almejando ao alcance da igualdade material. Assim, a preocupação do constituinte com o problema em tela pode ser observada nos artigos: $3^{\circ}$-inciso IV; $5^{\circ}$ - inciso I; $7^{\circ}$-incisos XVIII, XX e XXX; 40-inciso III, alíneas $a$ e $b$; e 226, parágrafo $5^{\circ}$.

Destarte, a República Federativa do Brasil se comprometeu internacionalmente a promover a igualdade de gênero e a eliminar o tratamento discriminatório da mulher. Nesse sentido, destacam-se: a Carta das Nações Unidas (1945); a Declaração sobre a Eliminação de Todas as Formas de Discriminação Contra a Mulher (1967); a Convenção Interamericana de Direitos Humanos (1969); a Convenção sobre a eliminação de todas as formas de discriminação contra a mulher (1979); a Declaração sobre a Eliminação de Violência Contra a Mulher (1993); a Convenção Interamericana para Prevenir, Punir e Erradicar a 
Violência contra as Mulheres (1994); a Declaração e Plataforma de Ação de Pequim (1995).

\section{TRATAMENTO DISCRIMINATÓRIO DA MULHER NO CRIME DE ABORTO}

De acordo com Bitencourt (2015), o aborto ocorre com a destruição da vida do embrião ou feto, entre o momento de sua concepção e o início do parto, que representa a etapa final da vida intrauterina. Dessarte, o autor também destaca que o abortamento pode ou não ser criminoso, e expõe que o aborto culposo é impunível.

O Código Penal brasileiro tipificou o aborto, em sua parte especial, nos crimes contra a vida, tanto aquele provocado pela gestante (art. 124), quanto o provocado por terceiros (arts. 125 e 126), ainda que com seu consentimento. O mesmo regramento também previu duas hipóteses nas quais o crime não é punido, quais sejam: o aborto necessário e o aborto em caso de gravidez resultante de estupro, com o consentimento da gestante (BRASIL, 1940).

Bitencourt (2015) define o aborto provocado como aquele em que a própria mulher é a responsável pelo abortamento. $\mathrm{O}$ aborto sofrido, por sua vez, ocorre sem o consentimento da gestante; e o aborto consentido é aquele com o qual a mulher autoriza, muito embora não o provoque. $\mathrm{O}$ autor destaca, ainda, que o bem jurídico tutelado nos crimes de aborto é a vida do feto ou embrião, e também a incolumidade da gestante no caso de crime de aborto provocado por terceiro.

De acordo com Nucci (2016), não há crime quando o aborto for natural, ou seja, quando a cessação da gravidez ocorrer de forma espontânea. Do mesmo modo, não há crime quando o abortamento for acidental, quando a interrupção da gravidez decorrer de causas exteriores-como choques ou quedas. $\mathrm{O}$ autor também destaca a figura do aborto permitido, no qual 
a cessação da gestação, que resulta na morte do feto/embrião, encontra respaldo na lei.

$\mathrm{O}$ aborto legal divide-se entre o aborto terapêutico ou necessário e o aborto sentimental ou humanitário. O primeiro abrange a interrupção da gravidez, efetuada por recomendação médica, com a finalidade de salvar a vida da gestante. Trata-se, portanto, de caso específico de estado de necessidade. Já o segundo consiste na autorização legal para cessar a gravidez de mulher que tenha sofrido estupro. Tratando-se de forma especial de exercício regular de direito (NUCCI, 2016).

Nucci (2016) também destaca que não há direito absoluto, o que inclui o direito à vida. Assim, é perfeitamente aceitável o aborto em casos excepcionais, a fim de que seja preservada a vida digna da mulher. No aborto necessário, o Direito optou pela vida da mãe, quando esta se encontra em conflito com a vida do feto ou embrião. Da mesma forma, no aborto humanitário, houve a prevalência da dignidade da pessoa humana, da mulher que sofreu violência sexual, em detrimento da vida do feto ou embrião. Para o autor, são dois valores essenciais, mas busca-se preservar aquele já existente.

Pelo fato de o Código Penal ser de 1940, e não ter sofrido alterações em relação aos dispositivos que tipificam o aborto, discute-se, atualmente, a constitucionalidade desse crime, especialmente no caso da prática voluntária pela gestante durante a fase inicial da gravidez. A questão ainda envolve muita polêmica e apresenta opiniões divergentes. Todavia, dois julgados dos tribunais superiores evidenciam a "mudança de pensamento" do Judiciário na tratativa do assunto, no que concerne à observância do tratamento diferenciado da mulher, a fim de garantir seus direitos.

Em abril de 2012, o Supremo Tribunal Federal (STF) julgou procedente a Arguição de Descumprimento de Preceito Fundamental (ADPF) n. 54, do Distrito Federal, para declarar 
a inconstitucionalidade, com eficácia para todos e efeito vinculante, do entendimento de que a interrupção da gravidez de feto anencéfalo é conduta típica, nos moldes dos arts. 124, 126, 128, incisos I e II, do Código Penal.

Tendo em vista que a ADPF n. 54 não visava à declaração da inconstitucionalidade abstrata dos artigos supracitados, mas tão somente que os enunciados dos dispositivos fossem interpretados em conformidade com a Constituição Federal, a fim de que as interrupções prescindissem de autorização, o STF não analisou a descriminalização do aborto naquela oportunidade.

Inicialmente, o Relator, Ministro Marco Aurélio, salientou a laicidade do Estado brasileiro, que foi preceituada pela Constituição de 1891, e persistiu nos textos constitucionais subsequentes. De acordo com ele, o Estado não é religioso ou ateu, mas simplesmente neutro:

[...] a garantia do Estado laico obsta que dogmas da fé determinem o conteúdo de atos estatais. Vale dizer: concepções morais religiosas, quer unânimes, quer majoritárias, quer minoritárias, não podem guiar as decisões estatais, devendo ficar circunscritas à esfera privada. A crença religiosa e espiritual - ou a ausência dela, o ateísmo - serve precipuamente para ditar a conduta e a vida privada do indivíduo que a possui ou não a possui. [...] Não podem a fé e as orientações morais dela decorrentes ser impostas a quem quer que seja e por quem quer que seja. Caso contrário, de uma democracia laica com liberdade religiosa não se tratará, ante a ausência de respeito àqueles que não professem o credo inspirador da decisão oficial ou àqueles que um dia desejem rever a posição até então assumida (BRASIL, 2012, p. 44, grifo nosso).

Esclarecendo que a análise do caso iria ser desprovida de dogmas religiosos, o Relator passou a discorrer acerca da anencefalia. Assim, expôs que o anencéfalo possui grave deficiência no plano neurológico, de forma que não dispõe de nenhuma função do sistema nervoso relacionada à cognição, à 
consciência, ao relacionamento, à comunicação, à emotividade e à afetividade. Faltam-lhe, além dos fenômenos da vida psíquica, a mobilidade, a sensibilidade, e a integração da grande maioria das funções corpóreas (BRASIL, 2012).

Por reiteradas vezes, o Relator alertou sobre a necessidade da observância dos direitos das mulheres, às quais cabe a decisão de prosseguir com a gestação ou interrompê-la. Nesse sentido, destacam-se os seguintes trechos:

[...] Se a proteção ao feto saudável é passível de ponderação com direitos da mulher, com maior razão o é eventual proteção dada ao feto anencéfalo (BRASIL, 2012, p. 67, grifo nosso).

[...] vale ressaltar caber à mulher, e não ao Estado, sopesar valores e sentimentos de ordem estritamente privada, para deliberar pela interrupção, ou não, da gravidez. Cumpre à mulher, em seu íntimo, no espaço que lhe é reservado - no exercício do direito à privacidade -, sem temor de reprimenda, voltar-se para si mesma, refletir sobre as próprias concepções e avaliar se quer, ou não, levar a gestação adiante. Ao Estado não é dado intrometer-se. Ao Estado compete apenas se desincumbir do dever de informar e prestar apoio médico e psicológico à paciente, antes e depois da decisão, seja ela qual for [...] (BRASIL, 2012, p. 76).

[...] $\mathrm{O}$ ato de obrigar a mulher a manter a gestação, colocando-a em uma espécie de cárcere privado em seu próprio corpo, desprovida do mínimo essencial de autodeterminação e liberdade, assemelha-se à tortura ou a um sacrifício que não pode ser pedido a qualquer pessoa ou dela exigido (BRASIL, 2012, p. 78).

Para o Ministro, é necessário ter empatia, solidariedade, aceitação e humanidade para com as mulheres que se encontrem em tal situação, as quais são as únicas capazes de mensurar o sofrimento vivenciado. A atuação com sabedoria e justiça, baseada na Constituição da República, e desprovida de ponderações morais e religiosas, obriga a garantir o direito da mulher de livre escolha (BRASIL, 2012). 
Assim como a histórica decisão da ADPF n. 54, o julgamento do habeas corpus (HC) n. 124.306, do Rio de Janeiro, também apresentou significativo posicionamento do Supremo Tribunal Federal em relação à aplicação do princípio da igualdade no tratamento dado às mulheres, e possível avanço no que concerne à descriminalização do aborto, cometido no primeiro trimestre da gestação.

Em novembro de 2016, o STF concedeu de ofício a ordem de habeas corpus para afastar a prisão preventiva de acusados da prática de aborto. No caso supramencionado, os pacientes do $\mathrm{HC}$ mantinham uma clínica de aborto, e foram presos em flagrante, pela suposta prática dos crimes de aborto com o consentimento da gestante e formação de quadrilha. Em síntese, a $4^{\mathrm{a}}$ Vara Criminal da Comarca de Duque de Caxias/RJ havia deferido a liberdade provisória aos pacientes, mas, no ano seguinte, a $4^{\text {a }}$ Câmara Criminal deu provimento ao recurso em sentido estrito, interposto pelo $\mathrm{MP} / \mathrm{RJ}$, a fim de decretar a prisão preventiva dos pacientes. Logo, a defesa impetrou o HC n. 290.341/RJ no STJ, que não foi conhecido pela Corte (BRASIL, 2016).

No HC n. 124.306, os impetrantes sustentaram que não estavam presentes os requisitos necessários para a decretação de prisão preventiva. Assim, em 2014, o Relator, Ministro Marco Aurélio, concedeu a medida cautelar pleiteada, em benefício dos pacientes. No ano seguinte, os efeitos da decisão foram estendidos aos demais corréus. No julgamento do HC, o Ministro votou pela admissão deste, e também pelo deferimento da ordem para afastar a custódia provisória, ratificando a liminar. Em seu voto-vista, o Ministro Luís Roberto Barroso apresentou uma série de argumentos relevantes, a fim de que os artigos penais que tratam da tipificação do aborto sejam interpretados em conformidade com a Constituição Federal, em observância ao princípio da igualdade e aos direitos mínimos das mulheres (BRASIL, 2016). 
Inicialmente, o Ministro defendeu que o processo deveria ser extinto, em razão da inadequação da via processual, mas salientou que, em decorrência da relevância da matéria, iria analisá-lo. Logo, passou a discorrer acerca da ausência dos requisitos que fundamentassem a decretação da prisão preventiva. Em sequência, o Ministro abordou a questão da inconstitucionalidade da criminalização da interrupção voluntária da gestação, no primeiro trimestre da gravidez. Para ele, a criminalização da conduta supracitada viola diversos direitos fundamentais da mulher e não condiz com o princípio da proporcionalidade (BRASIL, 2016).

Desse modo, destacou que o princípio da proporcionalidade visa a garantir o equilíbrio e a justiça dos atos estatais. De acordo com entendimento clássico, divide-se em três subprincípios: adequação, necessidade e proporcionalidade em sentido estrito. O subprincípio da adequação faz com que seja necessário analisar se a criminalização protege a vida do feto e, se o faz, em qual medida. Nesse sentido, recente estudo da Organização Mundial da Saúde demonstrou a ausência de impactos relevantes da criminalização em relação ao número de abortos. Ao contrário do que se espera, a taxa anual de aborto em países onde o procedimento é legalizado mostra-se menor do que a de países em que a prática é ilegal (BRASIL, 2016).

De fato, o que a criminalização compromete é o número de abortos seguros, prejudicando, assim, diversas mulheres que contraem complicações de saúde ou morrem em decorrência do procedimento realizado. Trata-se de um sério problema de saúde pública, especialmente em relação às mulheres pobres, que são privadas de assistência (BRASIL, 2016).

Acerca do posicionamento do Estado, em relação a esse tema, assim destacou o Ministro:

Em temas moralmente divisivos, o papel adequado do Estado não é tomar partido e impor uma visão, mas permitir 
que as mulheres façam sua escolha de forma autônoma. $\mathbf{O}$ Estado precisa estar do lado de quem deseja ter o filho. O Estado precisa estar do lado de quem não deseja - geralmente porque não pode - ter o filho. Em suma: por ter o dever de estar dos dois lados, o Estado não pode escolher um (BRASIL, 2016, p. 14, grifo nosso).

Para Barroso, a criminalização do aborto mostra-se ineficaz para evitar a interrupção da gestação e, por conseguinte, representa medida de questionável adequação para a tutela da vida do feto. Assim como reconheceu o Tribunal Federal Alemão, é necessário assentir que o Estado tem maiores chances de proteger o nascituro se trabalhar em conjunto com a mãe, não a tratando como uma criminosa (BRASIL, 2016).

No que tange ao subprincípio da necessidade, ressaltou que é preciso se certificar de que exista meio alternativo ao da criminalização, que proteja o direito à vida do nascituro, mas que apresente menor restrição aos direitos femininos. Nesse diapasão, o Ministro destacou que se deve reconhecer a existência de outros instrumentos eficazes à proteção dos direitos do feto e que apresentam menor potencial lesivo aos direitos da mulher. Um deles é o da descriminalização do aborto no período inicial da gravidez. Na Alemanha, por exemplo, a grávida que tem o intuito de abortar é submetida a uma consulta de aconselhamento e a um período de prévia reflexão (BRASIL, 2016).

Ademais, o Estado deve atuar sobre os fatores sociais e econômicos que ocasionam a gravidez indesejada, como a falta de informação ou de acesso a métodos contraceptivos. A atuação estatal deve considerar os fatores que levam as mulheres a abortar, como a impossibilidade de custeio da criação dos filhos, e a perda de oportunidades profissionais (BRASIL, 2016).

Outrossim, o subprincípio da proporcionalidade em sentido estrito alerta para a necessidade de identificação se as restrições aos direitos fundamentais das mulheres, em decorrência da criminalização, são compensadas, ou não, pela proteção à vida 
do feto. Dessa forma, é imperioso reconhecer o peso concreto do direito à vida do nascituro, o qual oscila de acordo com o estágio de seu desenvolvimento embrionário. A proteção constitucional ao feto é ampliada conforme a gestação avança, e este adquire viabilidade fora do ventre materno, conquistando maior peso concreto (BRASIL, 2016).

Assim como a Suprema Corte dos Estados Unidos decidiu no caso Roe v. Wade, o interesse estatal na proteção da vida pré-natal não ultrapassa o direito fundamental de a mulher realizar um procedimento abortivo. Nesse sentido, a Corte Suprema de Justiça do Canadá também declarou a inconstitucionalidade de dispositivo penal que criminalizava o aborto no país, em decorrência da violação do princípio da proporcionalidade. Ademais, praticamente nenhum país desenvolvido e democrático considera a interrupção da gravidez, em sua fase inicial, como crime (BRASIL, 2016).

Para analisar a questão, ainda, faz-se necessária a consideração acerca do status jurídico do embrião durante a fase inicial da gestação. Em suma, há dois posicionamentos divergentes em relação a este ponto. $O$ primeiro defende a existência da vida desde o momento da concepção, quando há a fecundação do óvulo pelo espermatozoide. O outro sustenta que não é possível se falar em vida sem a formação do sistema nervoso central, sem a origem da consciência, o que ocorre após o terceiro mês da gestação (BRASIL, 2016).

Conforme o Ministro, a controvérsia em questão não encontra solução jurídica pronta, uma vez que sempre dependerá da escolha religiosa ou filosófica de cada indivíduo em relação ao início da vida. Todavia, não há dúvida de que, até o terceiro mês de gestação, não exista a possibilidade de o embrião sobreviver fora do útero materno, dependendo integralmente do corpo da mãe (BRASIL, 2016).

No que diz respeito à violação da autonomia da mulher, 
destacou que a criminalização desrespeita sua liberdade individual e autodeterminação, uma vez que retira o direito da mulher de realizar suas próprias escolhas, decisões que refletem em seu corpo e em sua vida. Nas palavras do Ministro:

Quando se trate de uma mulher, um aspecto central de sua autonomia é o poder de controlar o próprio corpo e de tomar as decisões a ele relacionadas, inclusive a de cessar ou não uma gravidez. Como pode o Estado - isto é, um delegado de polícia, um promotor de justiça ou um juiz de direito - impor a uma mulher, nas semanas iniciais da gestação, que a leve a termo, como se tratasse de um útero a serviço da sociedade, e não de uma pessoa autônoma, no gozo de plena capacidade de ser, pensar e viver a própria vida? (BRASIL, 2016, p. 9, grifo nosso).

Dessarte, há a violação do direito à integridade física da mulher, tendo em vista que seu corpo estará suscetível aos riscos, transformações e consequências da gestação, ainda que indesejada. Da mesma forma, sua integridade psíquica é atingida pela assunção de uma responsabilidade que persistirá durante toda a vida, exigindo dedicação, renúncias, e comprometimento com outro ser. Impor à mulher a obrigação de ter um filho viola gravemente sua integridade psicofísica (BRASIL, 2016).

De acordo com Barroso, o tratamento dado ao tema pelo Código Penal brasileiro compromete a capacidade de autodeterminação reprodutiva da mulher. Em contrapartida, instrumentos internacionais têm desenvolvido a ideia da liberdade sexual feminina de forma positiva e emancipatória. Nesse sentido, destacou que:

[...] A sexualidade feminina, ao lado dos direitos reprodutivos, atravessou milênios de opressão. $\mathbf{O}$ direito das mulheres a uma vida sexual ativa e prazerosa, como se reconhece à condição masculina, ainda é objeto de tabus, discriminações e preconceitos. Parte dessas disfunções é fundamentada historicamente no papel que a natureza reservou às mulheres no processo reprodutivo. Mas justamente porque à mulher cabe o ônus da gravidez, sua 
vontade e seus direitos devem ser protegidos com maior intensidade (BRASIL, 2016, p. 10, grifo nosso).

Os dispositivos do Código Penal que tipificam o aborto também provocam a violação da igualdade de gênero, uma vez que a igualdade visa, dentre outros, a impor a extinção de injustiças históricas, sociais e econômicas. Dessa forma:

[...] A histórica posição de subordinação das mulheres em relação aos homens institucionalizou a desigualdade socioeconômica entre os gêneros e promoveu visões excludentes, discriminatórias e estereotipadas da identidade feminina e do seu papel social. Há, por exemplo, uma visão idealizada em torno da experiência da maternidade, que, na prática, pode constituir um fardo para algumas mulheres. Na medida em que é a mulher que suporta o ônus integral da gravidez, e que o homem não engravida, somente haverá igualdade plena se a ela for reconhecido o direito de decidir acerca da sua manutenção ou não. A propósito, como bem observou o Ministro Carlos Ayres Britto, valendo-se de frase histórica do movimento feminista, "se os homens engravidassem, não tenho dúvida em dizer que seguramente $o$ aborto seria descriminalizado de ponta a ponta" (BRASIL, 2016, p. 11, grifo nosso).

Ademais, as mulheres pobres são prejudicadas de forma desproporcional com a criminalização do aborto, pois não têm condições para arcar com médicos e clínicas particulares, e também não podem procurar o sistema público de saúde para efetuar o procedimento abortivo. Consequentemente, muitas recorrem a clínicas clandestinas, sem a mínima infraestrutura necessária, ou se submetem a procedimentos primitivos, que possuem altos riscos de lesões, mutilações e óbito (BRASIL, 2016).

O Ministro alertou para o fato de que o Código Penal brasileiro data de 1940, e, inobstante diversas atualizações realizadas à lei ao longo dos anos, ainda conserva a mesma redação em relação aos crimes tipificados nos arts. 124 a 128. Para Barroso, a defasagem da legislação foi evidenciada com a decisão do STF na ADPF n. 54. Logo, o aborto praticado até o terceiro 
mês de gravidez necessita ser revisto, em conformidade com os valores trazidos pela Constituição de 1988 (BRASIL, 2016).

No caso em tela, tendo em vista que o Código Penal é anterior à Constituição de 1988 , e a jurisprudência do STF não permite a declaração de inconstitucionalidade de lei anterior à $\mathrm{CF}$, a hipótese cabível, de acordo com o Ministro, foi a de não recepção, ou derrogação, dos tipos penais apontados. Por conseguinte, em razão da não incidência do tipo imputado aos acusados, por haver dúvida fundada sobre a própria existência do crime, houve o afastamento da decretação da prisão preventiva (BRASIL, 2016).

Apesar de os dois julgados aqui expostos representarem um grande avanço em relação ao tratamento dado à mulher no caso do aborto, há projetos de lei, que ainda estão em tramitação, que representam ameaça de retrocesso na tratativa do assunto.

Nesse sentido, o Projeto de Lei (PL) n. 478/2007 dispõe sobre o Estatuto do Nascituro e dá outras providências. Atualmente, o projeto está aguardando parecer do Relator na Comissão de Constituição e Justiça e de Cidadania (CCJC), e possui cinco outros projetos apensados a ele: PL n. 489/2007, PL n. 3748/2008, PL n. 1763/2007, PL n. 1085/2011, e PL n. 8116/2014.

O projeto em tela disciplina a proteção integral do nascituro, garantindo que o Estado, a sociedade e a família assegurarão os seus direitos com "absoluta prioridade". Dessa forma, o referido Projeto destaca que ao nascituro, nascido em decorrência de violência sexual, será assegurado, dentre outros, o "direito a pensão alimentícia equivalente a um salário mínimo, até que complete dezoito anos" (BRASIL, 2007a), obrigação que recairá sobre o Estado caso o genitor não seja identificado, ou se for insolvente.

A proposta também elenca crimes em espécie, com o intuito de tornar típicas, dentre outras, as seguintes condutas: 
"causar culposamente a morte de nascituro"; "anunciar processo, substância ou objeto destinado a provocar aborto"; "fazer publicamente apologia do aborto ou de quem o praticou, ou incitar publicamente a sua prática"; "induzir mulher grávida a praticar aborto ou oferecer-lhe ocasião para que o pratique" (BRASIL, 2007a).

Em suas disposições finais, o Projeto propõe a alteração dos arts. 124, 125 e 126, do Código Penal, a fim de estabelecer regime inicial mais gravoso para o delito de aborto provocado pela gestante ou com seu consentimento e aumentar as penas dos crimes de aborto provocado por terceiro. Ademais, também houve a previsão de que tais dispositivos, juntamente com o art. 127 (que trata da forma qualificada do aborto), fossem acrescidos à Lei dos Crimes Hediondos (BRASIL, 2007a).

No mesmo sentido, o Projeto de Lei n. 489/2007 também dispõe sobre o estatuto do nascituro e dá outras providências. Muito embora esse projeto seja bastante semelhante ao PL $\mathrm{n}$. 478/2007, a justificação manifesta-se da seguinte forma: "a pena para o aborto será cadeia de verdade! Parece até um sonho diante da impunidade reinante neste país para quem mata criancinha". E ainda: "queira Deus que esta Casa de Leis se empenhe o quanto antes em aprovar este Estatuto, para a alegria das crianças por nascer e para orgulho desta pátria" (BRASIL, 2007b, p. 8).

Em consonância com o objetivo dos projetos anteriores, o Projeto de Lei n. 3748/2008 autoriza o Poder Executivo a conceder pensão à mãe que opte por manter a criança nascida de gravidez decorrente de estupro. Todavia, o Projeto em questão diverge um pouco dos projetos anteriores, em relação à duração do benefício e ao responsável pelos pagamentos. Enquanto estes preveem o pagamento de pensão à criança, cuja mãe foi vítima de estupro, até os 18 anos, e com responsabilidade principal do estuprador; aquele onera o Poder Público ao pagamento de tal benefício, até que a criança complete 21 anos de 
idade (BRASIL, 2008).

Ainda de acordo com o projeto, para receber a pensão, a mulher deve efetuar o cadastramento junto ao Ministério de Assistência Social, apresentando "cópia autenticada do registro policial de ocorrência", "laudo do Instituto Médico Legal", e "cópia autenticada da certidão de nascimento da criança" (BRASIL, 2008).

Outro Projeto de Lei que visa à assistência para a mãe e o filho gerado em decorrência de estupro é o PL n. 1763/2007. No que concerne à assistência da mulher grávida, vítima do estupro, a proposta destaca que, no delito reconhecido por decisão transitada em julgado, o Poder Público deverá: disponibilizar gratuitamente assistência social, psicológica e pré-natal; orientar sobre os procedimentos de adoção; conceder à mãe o "pátrio poder", e o benefício mensal de um salário mínimo até que a criança complete 18 anos (BRASIL, 2007c).

Na justificativa do respectivo Projeto, foi defendido que:

Punir a criança com a morte por causa do estupro de seu pai é uma injustiça monstruosa. Mais monstruosa que o próprio estupro. Será justo que a mãe faça com o bebê o que nem o estuprador ousou fazer com ela: matá-la?

Entendemos que o aborto é mais monstruoso que o estupro.

$[\ldots]$

[...] E, para decepção dos penalistas que defendem o aborto em tal caso, a convivência com a criança não perpetua a lembrança do estupro, mas serve de um doce remédio para a violência sofrida. Não se conhece um só caso em que uma vítima de estupro, após dar a luz, não se apaixonasse pela criança.

E mais: se no futuro, a mulher se casa e tem outros filhos, o filho do estupro costuma ser o preferido. Tal fato tem uma explicação simples na psicologia feminina: as mães se apegam de modo especial aos filhos que lhes deram maior trabalho. 
A existência de uma não punição para o aborto em tal caso (art. 128, inciso II, do Código Penal) é uma vergonha nacional. [...] (BRASIL, 2007c, grifo nosso).

O Projeto n. 8116/2014 também dispõe sobre a proteção ao nascituro. Com disposições semelhantes aos Projetos de Lei $n$. 478/2007 e n. 489/2007, o PL n. 8116/2014, todavia, não trouxe a previsão do auxílio financeiro mensal que os dois projetos almejam. Porém, apresentou a possibilidade de concessão de auxílio estatal no caso de a mãe, vítima do estupro, não possuir meios econômicos suficientes para cuidar da criança, mas somente até que o "genitor" seja identificado e responsabilizado pela pensão, ou quando a criança for adotada (BRASIL, 2014).

Em contrapartida aos projetos supracitados, que visam, inclusive, a criminalizar toda forma de aborto, o Projeto de Lei n. 1085/2011 dispõe sobre a assistência para a mulher vítima de estupro que optar pelo aborto legal. Tal assistência consistiria no pagamento de uma bolsa auxílio de um salário mínimo, por um período de três meses, à grávida vítima de estupro, que opte pelo aborto ou que decida prosseguir com a gravidez, mas sofra aborto espontâneo (BRASIL, 2011).

O último Projeto de Lei apensado, o PL n. 882/2015, pretende estabelecer políticas públicas no âmbito da saúde sexual e dos direitos reprodutivos das mulheres, bem como regular as condições da interrupção voluntária da gravidez. Assim, o Projeto prevê o direito da mulher a interromper voluntariamente a gravidez na fase inicial da gestação. Após esse período, o Projeto somente autoriza a interrupção da gestação em determinados casos, que atendam aos requisitos lá previstos. Ademais, foi estabelecido que as mulheres que procurarem pelo procedimento receberão toda a informação necessária, e só serão submetidas ao procedimento após seu consentimento expresso e por escrito (BRASIL, 2015).

Em sua justificativa, o PL n. 882/2015 sustenta que há es- 
timativas de que ocorram anualmente no Brasil de 729 mil a 1 milhão de abortamentos inseguros, apesar de a prática ser ilegal. Também foi arguido que uma em cada sete brasileiras, com idade entre 18 e 39 anos, já realizou ao menos um aborto na vida. Entre os 35 e 39 anos, a taxa é ainda maior: uma em cada cinco brasileiras. Tais dados demonstram a magnitude do abortamento no país, independentemente da vedação legal, o que implica uma questão de saúde pública, e não de direito penal (BRASIL, 2015).

Nesse sentido, foi destacado que os abortamentos clandestinos ocorrem, em sua maioria, por meio de procedimentos efetuados sem assistência e padrões sanitários adequados, resultando em complicações, como hemorragia, infecção, infertilidade e morte. A criminalização do aborto não leva à eliminação, ou redução, do número de casos no Brasil, mas representa uma das principais causas de morte materna no país. O discurso de "defesa da vida" do feto ignora o fato de que a criminalização do aborto mata (BRASIL, 2015).

Outrossim, o PL n. 882/2015 defendeu que a interrupção voluntária da gravidez é um processo difícil para as mulheres, e que não é usado como método contraceptivo. Do mesmo modo, não se trata de prerrogativa de adolescentes e jovens mulheres, pois muitas das que realizam o procedimento têm mais de dois filhos e relações conjugais estáveis. O Projeto ainda expôs que o Brasil enfrenta o atraso na tratativa do assunto pelo fato de parlamentares integrantes de frentes antiaborto ocuparem, em maioria, as comissões que avaliam e votam os projetos de lei concernentes aos direitos das mulheres (BRASIL, 2015).

\section{ANÁLISE SOBRE O TRATAMENTO DISCRIMI- NATÓRIO DA MULHER NO CRIME DE ABORTO}

Ante o exposto no segundo capítulo, pode-se concluir que a observância da igualdade formal assegura às mulheres os mes- 
mos direitos juridicamente garantidos aos homens, sem tratamento discriminatório. Após o reconhecimento e a garantia dos direitos femininos, busca-se atingir a igualdade material, com a adoção de medidas que visam a diminuir e erradicar as assimetrias de poder construídas com base no gênero, que submeteram as mulheres à violência e tratamento desigual por tantos anos.

No que tange ao delito de aborto, a discussão acerca da (in)observância do princípio da igualdade na atual criminalização das mulheres que, na fase inicial da gravidez, provocam o abortamento de seus fetos, ou de terceiros que o fazem com seu consentimento, encontra entraves de ordem moral e religiosa, historicamente enraizados na sociedade e reproduzidos na esfera jurídica.

Todavia, conforme frisado no estudo, a decisão do Supremo Tribunal Federal no julgamento da ADPF n. 54, em 2012, que declarou a inconstitucionalidade do entendimento de que a interrupção da gravidez de feto anencéfalo é conduta típica, representou o primeiro passo no que tange ao reconhecimento da igualdade de gênero na questão do aborto.

Por conseguinte, o voto-vista do Ministro Luís Roberto Barroso na apreciação do HC n. 124.306, em 2016, também apresentou significativo posicionamento do STF em relação à aplicação do princípio da igualdade no tratamento dado às mulheres, observando os preceitos constitucionais, e conforme os compromissos assumidos internacionalmente pela República Federativa do Brasil nas convenções e declarações apresentadas no segundo capítulo.

Os dois julgados expostos no presente estudo representam um grande avanço em relação ao tratamento diferenciado favorável à igualdade de gênero, e à proteção dos direitos humanos e fundamentais das mulheres. O próximo passo será a discussão, e decisão, acerca da descriminalização do aborto voluntário praticado na fase inicial da gestação. 
Todavia, conforme foi apresentado na seção anterior, há projetos de lei que constituem verdadeira involução, uma vez que pretendem tipificar toda forma de aborto, agravar as penas já existentes, e até fornecer uma espécie de compensação financeira para as mulheres que optarem por não interromperem a gravidez decorrente de estupro. Tais propostas representam uma afronta aos Direitos Humanos, e correspondem à imposição do pensamento religioso de determinada parcela da sociedade a todos, de forma desigual e generalizada, ignorando o grave problema de saúde pública do país, e contribuindo para a discriminação da mulher em razão do gênero.

Com base nos projetos de lei apresentados, pode-se extrair o entendimento de que aqueles contrários à descriminalização do aborto, e que visam a manter a gestação do feto até nos casos de estupro (cujo aborto humanitário é permitido pelo Código Penal) corroboram com a prática da violência de gênero, uma vez que apresentam justificativas pautadas em credos de ordem moral e religiosa para onerar, ainda mais, as mulheres que já se encontram em situação de desigualdade.

A discriminação da mulher pode ser observada em diversos trechos dos projetos de lei sobre o tema, de forma tácita ou explícita. Nesse sentido, as disposições que atribuem às mulheres, que recorrem ao aborto, caráter de perversidade ainda mais grave do que aquele socialmente dado aos estupradores, e as que consideram que a manutenção do feto, decorrente de estupro, servirá para a mulher como "um doce remédio" pela violência sofrida desprezam completamente os direitos femininos e a questão da igualdade. Tais preceitos também contribuem para a perpetuação e legitimação da violência contra a mulher em razão do gênero.

A ausência de justificativa plausível que embasasse esses projetos é nítida quando até Deus é invocado para acelerar a aprovação de uma lei. Do mesmo modo, o condicionamento da 
concessão de um benefício financeiro (que, por si só, já é absurdo) à comprovação da violência sofrida pela mulher (inclusive com os requisitos de apresentação de "cópia autenticada do registro policial de ocorrência" e de "laudo do Instituto Médico Legal") manifesta-se ultrajante. Não bastasse a violência sofrida, a mulher ainda teria que se sujeitar a um sistema burocrático, revivendo o ato de violência, para receber tal "benefício".

A ideia de que o Poder Público arque com um auxílio mensal até que a criança, proveniente do estupro, atinja a maioridade é, no mínimo, assustadora. Desse modo, busca-se abafar o problema da violência de gênero, que tem sido exposto e discutido com mais veemência nos últimos anos, e ainda fazê-lo com o dinheiro público. $\mathrm{O}$ benefício financeiro previsto pelos projetos manifesta-se como uma forma de conivência estatal para com o fenômeno social da violência contra a mulher por motivo de gênero, cuja uma das formas é o estupro. Assim, busca-se comprar o silêncio das vítimas de um histórico e cultural tratamento discriminatório, e também perpetuar situações de manifesta desigualdade.

Ao invés de se fornecer uma espécie de "compensação" financeira pela violência sofrida, que o dinheiro público seja, então, aplicado em programas e políticas voltadas à conscientização e educação de gênero, bem como ao combate e prevenção da violência de gênero, a fim de erradicar sua prática. Que as mulheres e meninas, vítimas de tais violências, recebam o apoio necessário e um tratamento de qualidade e humanitário, quer optem por prosseguir com a gestação, quer não.

Ainda sobre os projetos de lei que envolvem a questão do aborto, os PL's n. 1085/2011 e n. 882/2015 apresentam respostas relevantes e coerentes à questão do aborto. Nesse sentido, o apoio e a informação à mulher que se encontra em situação de desigualdade são imprescindíveis para que o número de mortes diminua, e para que a discriminação baseada 
em relações desiguais de poder não prevaleça sobre os direitos mínimos das mulheres.

Em contrapartida ao atual tratamento discriminatório dado à mulher que recorre ao abortamento do embrião ou feto, a descriminalização do aborto voluntário na fase inicial da gravidez atende ao princípio da igualdade, uma vez que concede à mulher tratamento diferenciado, em razão de sua desigualdade de fato, e manifesta-se como medida adequada, proporcional e razoável.

Nesse sentido, pode-se concluir que tratar as mulheres em situação de desigualdade como criminosas não apresenta eficácia prática, em relação ao bem jurídico que o tipo penal visa proteger: a vida do feto. Em contrapartida, a criminalização agrava um sério problema de saúde pública no país, uma vez que inúmeras gestantes que se submetem a procedimentos abortivos clandestinos, por falta de amparo e de escolha, acabam contraindo complicações e, em muitos casos, até morrendo.

Impossibilitar a escolha da mulher e criminalizar o aborto no primeiro trimestre da gravidez, quando não há expectativa de vida extrauterina, é medida que se apresenta discriminatória, desproporcional e desumana. A criminalização da interrupção da gravidez, nas primeiras semanas, fere diversos direitos fundamentais das mulheres, como a autonomia, a integridade física e psíquica, direitos sexuais e reprodutivos, bem como a igualdade de gênero.

Em síntese, o presente estudo expôs que a criminalização da interrupção da gestação, cometida no primeiro trimestre, desrespeita o princípio da igualdade, pois onera a mulher de forma desproporcional, bem como prejudica significativamente o núcleo essencial de seus direitos fundamentais, ultrapassando os limites constitucionalmente aceitáveis.

\section{CONCLUSÃO}

Com a pesquisa, foi constatado que o princípio da igualda- 
de abrange a igualdade formal e a igualdade material, as quais são complementares. Nesse sentido, destacou-se que enquanto a igualdade formal assevera que todos são iguais perante a lei, sem discriminações, a igualdade material assegura que os diferentes recebam tratamento diferente, a fim de não agravar a desigualdade já existente.

Com base nas informações levantadas, concluiu-se que o objetivo geral do artigo foi alcançado, uma vez que foi observado que a criminalização do aborto, na forma em que ocorre atualmente, não atende ao princípio da igualdade e corrobora com o tratamento discriminatório de gênero. Nesse sentido, pôde-se notar que houve um grande avanço na tratativa do tema, em decorrência dos julgamentos da ADPF n. 54 e do HC n. 124.306 pelo STF. Todavia, há projetos de lei, que se encontram em tramitação, que ameaçam agravar, ainda mais, a situação de desigualdade das mulheres.

\section{REFERÊNCIAS}

BITENCOURT, Cezar Roberto. Código penal comentado. 9. ed. São Paulo: Saraiva, 2015.

BRASIL. Decreto-lei n. 2.848, de 7 de dezembro de 1940. Código penal. Disponível em: <http://www.planalto.gov.br/ccivil_03/decreto-lei/del2848.htm>. Acesso em: 23 jul. 2016.

Câmara dos Deputados. Projeto de lei n. 478/2007. 2007a. Disponível em:

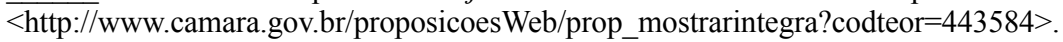
Acesso em: 16 jan. 2017.

Câmara dos Deputados. Projeto de lei n. 489/2007. 2007b. Disponível em: < http://www.camara.gov.br/proposicoesWeb/prop_mostrarintegra?codteor $=444066 \&$ fil ename $=P L+489 / 2007>$. Acesso em: 16 jan. 2017.

. Câmara dos Deputados. Projeto de lei n. 1763/2007. 2007c. Disponível em: < http://www.camara.gov.br/proposicoesWeb/prop_mostrarintegra?codteor $=490988 \&$ filename $=P L+1763 / 2007>$. Acesso em: 16 jan. $20 \overline{17}$.

. Câmara dos Deputados. Projeto de lei n. 3748/2008. 2008. Disponível em: < http://www.camara.gov.br/proposicoesWeb/prop_mostrarintegra?codteor $=587119 \&$ fil ename $=\mathrm{PL}+3748 / 2008>$. Acesso em: 16 jan. $201 \overline{7}$.

. Câmara dos Deputados. Projeto de lei n. 1085/2011. 2011. Disponível em: <

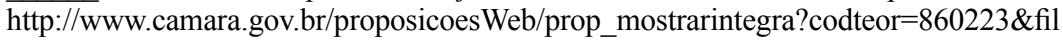


ename $=P L+1085 / 2011>$. Acesso em: 16 jan. 2017.

- Câmara dos Deputados. Projeto de lei n. 8116/2014. 2014. Disponível em: <http://www.camara.gov.br/proposicoesWeb/prop_mostrarintegra?codteor $=1287642 \&$ filename $=P L+8116 / 2014>$. Acesso em: 16 jan. 2017.

. Câmara dos Deputados. Projeto de lei n. 882/2015. 2015. Disponível em: $\overline{<\mathrm{http} / /}$ www.camara.gov.br/proposicoesWeb/prop_mostrarintegra?codteor $=1313158$ $\&$ filename $=P L+882 / 2015>$. Acesso em: 04 fev. 2017.

. Supremo Tribunal Federal. $A D P F$ 54/DF 31: Arguição de Descumprimento de Preceito Fundamental 54 Distrito Federal. 2012. Disponível em: < http://www.stf.jus. br/arquivo/cms/noticianoticiastf/anexo/adpf54.pdf $>$. Acesso em: 08 ago. 2016.

. Supremo Tribunal Federal. Habeas corpus n. 124.306 Rio de Janeiro. 2016. Disponível em: < http://www.stf.jus.br/arquivo/cms/noticiaNoticiaStf/anexo/ HC124306LRB.pdf>. Acesso em: 08 ago. 2016.

CASTILHO, Ricardo. Direitos humanos. 5. ed. São Paulo: Saraiva, 2015.

FERREIRA FILHO, Manoel Gonçalves. Princípios fundamentais do direito constitucional: o estado da questão no início do século XXI, em face do direito comparado e, particularmente, do direito positivo brasileiro. 4. ed. São Paulo: Saraiva, 2014.

MIRANDA, Jorge. Sobre o princípio da igualdade. In: LINHARES, Emanuel Andrade; MACHADO SEGUNDO, Hugo de Brito (Org.). Democracia e direitos fundamentais. Uma Homenagem aos 90 anos do Professor Paulo Bonavides. Rio de Janeiro: Atlas, 2016. p. 415-443.

MORAES, Guilherme Peña de. Curso de direito constitucional. 8. ed. Rio de Janeiro: Atlas, 2016.

NUCCI, Guilherme de Souza. Manual de direito penal. 12. ed. rev., atual. e ampl. - Rio de Janeiro: Forense, 2016.

PINHO, Rodrigo César Rebello. Teoria geral da constituição e direitos fundamentais. 15. ed. Vol. 17. São Paulo: Saraiva, 2015.

STREY, Marlene Neves. Violência e gênero: um casamento que tem tudo para dar certo. In: GROSSI, Patrícia K; WERBA, Gabriela C. (Org.). Violências e gênero: coisas que a gente não gostaria de saber. Porto Alegre: EDIPUCRS, 2001. p. 47-69.

Artigo recebido em: 28/05/2017

Artigo aprovado em: 04/10/2017 